\title{
VIRTUALCLASSROOM AN EASY AND LOW COST SOLUTION TO E-LEARNING SYSTEM
}

\author{
SYED FAROOQ ALI ${ }^{1}$, HAMZA TAHIR $^{2}$, ZAFAR KHAN $^{3}$ \\ ${ }^{1}$ Department of Software Engineering, University of Management and Technology, Lahore, Punjab, Pakistan \\ Email: farooq.ali@umt.edu.pk
}

\begin{abstract}
E-Learning and Virtual Classroom applications have gained a lot of popularity due to growing population, easy access and low cost solution. The study in this paper proposes an open source Virtual Classroom application that tends to mimic all the functionalities and features of real class room. Its interface designs are based on the online learning theories. It will provide the students and teachers $a$ real time virtual platform, where they can learn, share and properly propagate their knowledge, views and ideas. This open source application allows the faculty members to conduct all the class activities as if they are in real classroom. On the other hand, students have the advantage of raising questions during the lecture with the help of a chat box and a white board. In order to assess the interfaces of this application, Micrsoft Visual Studio 2012 has been used. Our application provides security and reliability to all its users. All the courses, students and faculty members are managed in a real time using this application. Administrator handles all these procedures, and has all the rights over the system including the users and databases.
\end{abstract}

Keywords: Epidemic models; Homotopy Perturbation Method; Numerical simulations.

1. Introduction. Virtual classroom enables universities and colleges to deliver a high-quality learning experience to remote students. Our application is an integrated e-learning environment for students and faculty members. This project aims at putting together an integrated e-Learning environment for a university student without relying on attending the real classroom. This will also be used by distance education programs offered by institutes, in order to enable students to avail the academic facilities from any computer connected to our application through internet [2], [16]. Our project aims at providing equal opportunities for those who are restricted to study at their homes. In Pakistan many communities still follow strict traditions and they don't allow their children especially females to go out to regular schools, colleges and universities. They are stranded in their homes and are unable to make their future secure and successful by seeking education. Our system will not only allow the people to follow their traditions but also gain knowledge and quality education online i.e. by sitting in their homes [19].

Another important factor that initiates the need of developing virtual classroom is the population of rural areas. Major population of developing countries including Pakistan, India etc., is living in rural areas where they they don't have that much opportunities of education, as the institutes in rural areas are not up to the mark. This project will significantly reduce the difficulties of getting quality education for the students of rural areas. Furthermore, long distances, expensive and low quality transportation system demand the need of Virtual Classroom. Another important factor that motivates us for Virtual Classroom development was existence of education with lack of resources[2]. In developing countries including Pakistan, India, Bangladesh, Malaysia etc. it is difficult to build enough institutes and impart cheap education to the people. 
2. Literature Review. The original Virtual Classroom program was launched by AT\&T in the fall of 1996 [6]. During the period of 1996 through 2000, over 19,000 students from dozens of countries around the world used it to collaborate, communicate and learn about them, and about the Internet [1].

There are many existing applications similar in functionality to our Virtual Classroom, but some of them are for specific purposes, some support offline communication and some are for conferencing purposes like BigBluebuttons and Virtual University of Pakistan[19]. BigBluebuttons supports online conferencing and live lecture delivering options while Virtual University of Pakistan uses recorded sessions and offline communications. KMC Virtual Classroom uses online video and audio streaming, survey polls and exams Error! Reference source not found.. Moodle is also one of the most popular open source e-learning systems. It is built with PHP \& uses MySQL or PostgreSQL to store data Error! Reference source not found.. It has powerful course management features that cover creating lessons, assignments, quizzes, documents \& more. There are various modules [16]that help students \& teachers to interact with each other like chat, forum, survey or workshop [17]-[17]. The problem with moodle is that it does not represent virtual environment. There has been an increasing trend regarding usage of facebook as Virtual Classrooms in many countries [8]. Moreover, gamification of virtual classrooms by adding leaderboards are frequently discussed trends in education [12]. Resource managers and resource sharing systems also exist for distance education systems [20], [25]. Virtual classroom has lot of applications in e-governance. Our system has the advantage of having virtual environment. These features makes our application similar to the above mentioned applications, though there are some differences like in the online quiz, as we don't provide the result as soon as the quiz is taken but it is evaluated later by the resource person and the result is then uploaded to the report page. The other main difference is that the student doesn't register themselves directly. First, they have to interact with the system administrator. Similarly courses and faculty members are also not registered directly; they also have to be managed by administrator. The inclusion of Chat box makes it even much better as it allows faculty and students to add friends and have discussion via online chat. The history of chat is also stored in database and can be retrieved later. Our application will not only help in reducing education costs but will also improve quality of education [3].

3. Functions and Features. The Virtual Classroom ${ }^{1}$ is an open source application that has such features and functions which makes it very feasible e-learning environment [3]. Some of the features are new and some are the basic features of a typical virtual classroom. We have tried to mimic the virtual classroom functionalities in our application and have provided the various features. The main features of our virtual classroom lie with the fact that it will provide a virtual environment to the students as well as the teachers. It will not be real but it will feel as if it is real because it has the login management, course management system, quiz management system, students management system, faculty management system, database management system, news management system, time table, discussion forum, the ability to upload and download course material, chat box, besides we tried to maintain the confidentiality of the users (Student, Teacher, Administrator). In the course management system the users i.e. faculty members, students and administrators have access to it. This section provides the students to register their course (approved by the administrator) and also to view all the course materials. The student can download all the course material if the teacher allows it. All the course details for a specific subject can be viewed by all the users. The faculty members have the access to upload course related material to the section of individual subjects. In this section, the administrator has the right to manage all the procedures, course addition, course removal and modification of existing courses. In the student management system, the administrator and the faculty members perform various activities. The administrator manages all the students, their records and profiles. The faculty members can view the profile of each student and also their progress reports and registered courses. Faculty management system is managed by the administrator; i.e. he can remove, add new and modify existing profile. The students can only view the profile of teachers and can interact with them via email. Database is fully managed by the administrators; the administrator can make changes accordingly in all the sections mentioned above. There will also be an announcement section which will contain all the important news, announcements and the time table. Students only can view the news and time table, however, the administrator and faculty can post and modify announcements and timetable. There will also be a discussion forum for all the users that will be managed by the administrator. The students and faculty members can have discussion on this forum. It works by posting text, image or file and then other members can comment

\footnotetext{
${ }^{1}$ The Virtual Classroom can be downloaded from this link https://sites.google.com/site/farooqlus/code
} 
in that specific post. The students and faculty can upload files as well as can download them. All these posts are managed by administrators and to avoid any inappropriate posts, the administrator has been given authority to delete that post and also to warn the concerned person. In response to a problem posted by someone, all the members of the discussion forum can suggest solution by commenting on that problem. This is an excellent way of improving the interaction between the students and the faculty members and also among the students themselves. Besides, uploading and downloading all the material including slides, handouts, quiz solutions, project descriptions, and assignment descriptions etc., the students can also register their courses, view their results, check notices, and interact with fellow students and teachers as well. There will be a discussion forum for all the users, in which they can upload their queries. Student or faculty who has the answer to this query can provide the reply in the comment box and they can also upload related material. Other students can like and comment on that specific post. This will make the interaction much better. Another main feature is the quiz time i.e. the resource person can upload a quiz online to the students and can set a particular time for the students. The students are meant to solve the quiz within the given time frame otherwise the quiz page will turn over when the time is up. The quiz will be automatically saved in the resource person's given directory. After the quiz is graded, the teacher will upload the solution along with the report to each individual student. Each student will be informed regarding announcements, important news and events via an email, because some students might not be able to see the notice board. Students will also have the option to register themselves in a particular course; this makes the choice of selection much convenient for both the students and administrators. All the above mentioned features are mostly for the students and the teachers; however there are some specific features only for the administrator to handle the processes. The administrator will be able to manage faculty, discussion forum, students, users, courses, news, events, databases and registration. The administrator will have to manage the entire faculty; faculty members can be added, removed and courses can be assigned to specific faculty members by the administrator. The course along with all its content will be given to the faculty member. The administrator will have all the rights over faculty; administrators can also review the performance of the faculty members. The students will also be managed by administrators. Administrator can add, remove, block and update the profiles of new students. Students will be registered according to their courses. Administrator also has all the rights over a student like viewing his profile, check his progress report and also his performance accordingly. The administrator has to manage courses; he has to provide a list of courses to be offered in a specific semester. He has to register courses for the students and also assign courses to faculty members. News, events and important updates are to be managed by the administrator; he has to update any particular news or event on the notice board, and also has to send an email to each individual student about that particular news.

4. System Architecture. There are already many virtual classroom applications; some of these applications are similar and some are different in their functionality and performance as compared to our proposed application. Some supported various features that are similar to the features of our virtual classroom. These include white board, course management, system management, faculty and student management, registration, video and audio streaming. But there were some modifications that we will implement in our application. Video Streaming is an excellent feature that can be implemented in future. These modifications will be in streaming for which we will use dedicated server for controlling the traffic; this will improve the streaming when there is much traffic. More servers can be added for load balancing. The other thing that will be improved by us is the use of content management system and uploading/downloading of materials in discussion forum. Whenever there is a new post, all the authorized members will be notified about this new post. Members can comment, i.e. like and also add their views about this specific post. There is a Quiz Management System in our application where the quizzes can be conducted and their results will be uploaded. Quiz time check is implemented in our application and hence, after the completion of the quiz time, the system would automatically move to the next page. The difference comes in testing the Interfaces using a standard tool i.e. Microsoft Visual Studio 2012 Ultimate. This tool is used to test all the interfaces of our application. We have tested it for each individual use case and generated a code accordingly. This helped us in evaluating usability of our interfaces. The basic architecture of Virtual Classroom is Client-Server Architecture. The system will run on both client and server side and should be installed properly. 
A. Communication Architecture: The communication of Virtual Classroom will be between client and server and database servers. It will use the TCP/IP protocol.

It will be based on Multi-tier architecture

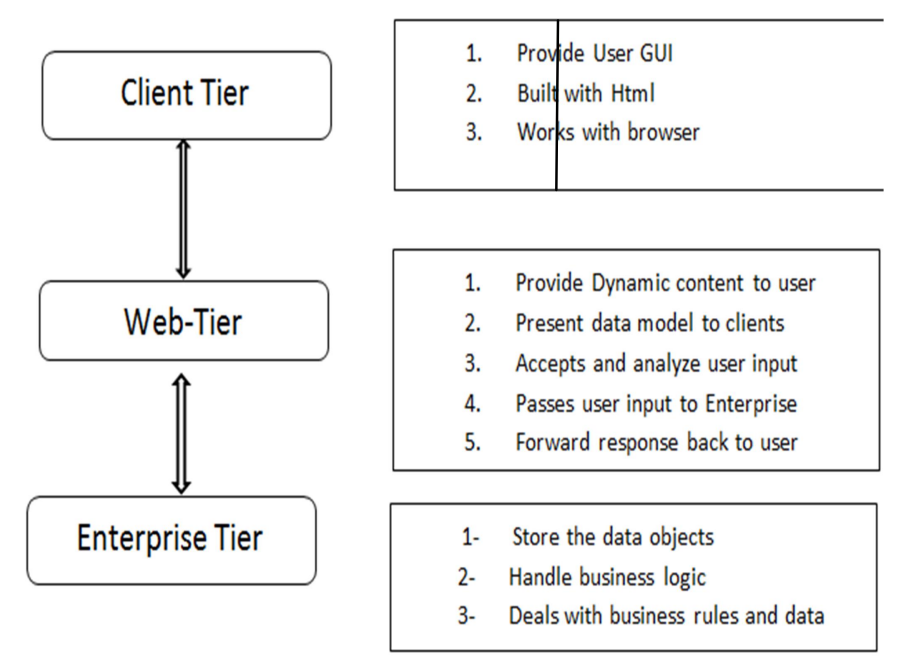

Figure 1:- Multi-Tier Architecture

The Figure-1 shows the different layers of the multi-tier architecture including GUI, business logic and data layer that are used for efficient communicationError! Reference source not found.. The protocols that we mentioned above are used for the transmission of data. TCP is used for streaming reliable data although it is slow, because it re-transmits the broken data packets hence this slows downs the transmission of data, however, UDP is fast and doesn't slows down for the re transmission because it doesn't care for the lost packets of data or re transmitting them [20]. This 3 layer architecture is also called MVC architecture and is based on 3 Tier [6]. It has three layers Presentation, Logic and Data layer. The presentation layer is the interface where we make a request whereas the middle layer is the logical layer where logical decisions and evaluations are made. It also works as an intermediate between the two layers. Third layer is the Data layer, consisting of the databases and file systems, where the information is retrieved and passed to the logical layer and then to the user.

The reason we implemented 3 Tier-Architecture is that it is exceptional in security and it is also very scalable and the other major factor is the speed of its executions, but there are some disadvantages as well of this system, i.e. is that it is very costly.

5. Evaluation of Interfaces with Visual Studio 2012 Ultimate: To improve our interfaces we have used a software tool Microsoft Visual Studio 2012 Ultimate Error! Reference source not found.. This software is for the testing of interfaces. It generates a code for each action we performed during the recording Error! Reference source not found. Assertions have been made on specific use case. We ran the application for almost each use case and in response got the result of failure and success. Those cases which failed the test were re-modified. This tool really helped us in making the interfaces according to the standards and very interactive to the user [14]. All our interfaces are according to the Coded UI testing of Visual Studio 2012 Ultimate. There are some figures shown below that provides the explanation of the tests that we perform. 


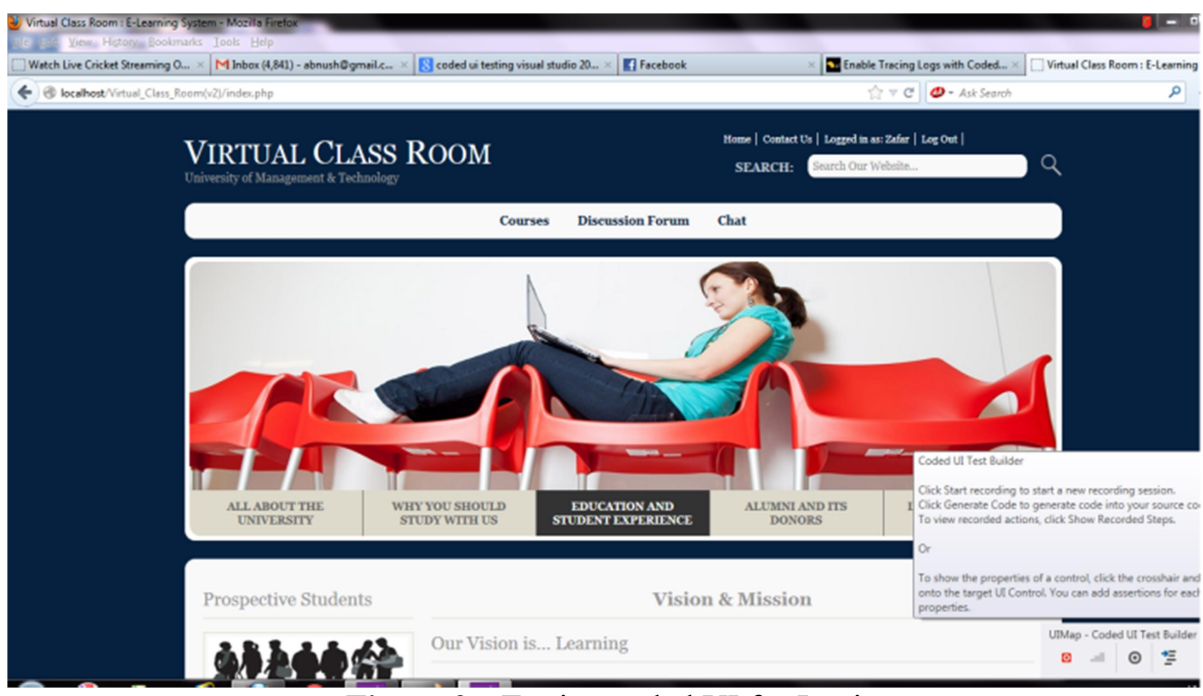

Figure 2:- Testing coded UI for Login

This is the first step by starting recording for testing the login use case. This will record each step that we perform.

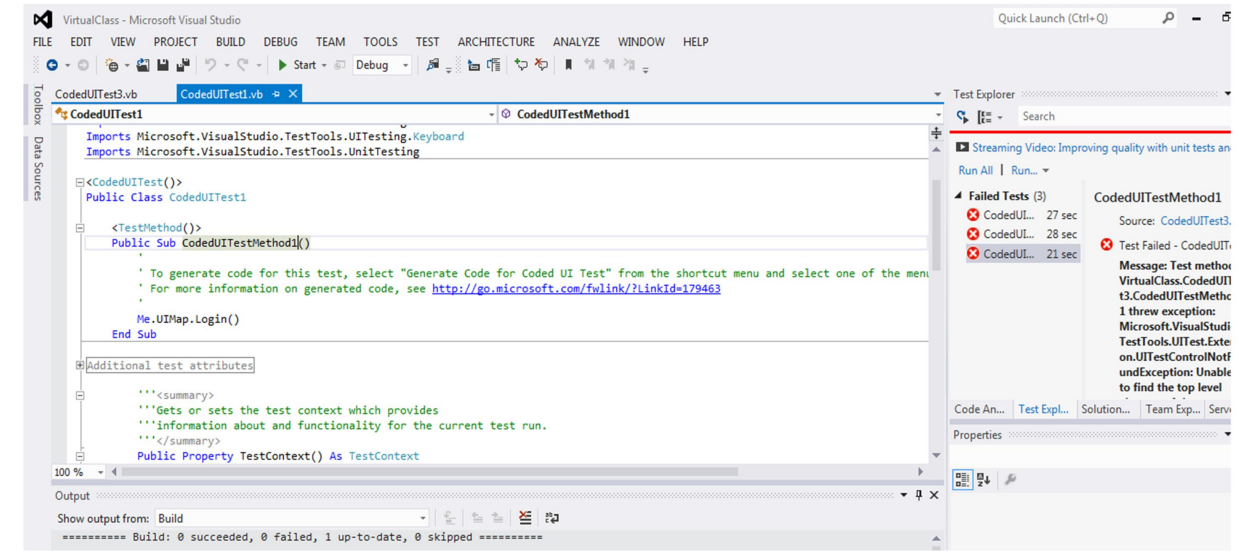

Figure 3:- Code Generation Login

After recording the steps of logging in, Figure-3 is generated for the use case login test. This code is than built and run after words. 


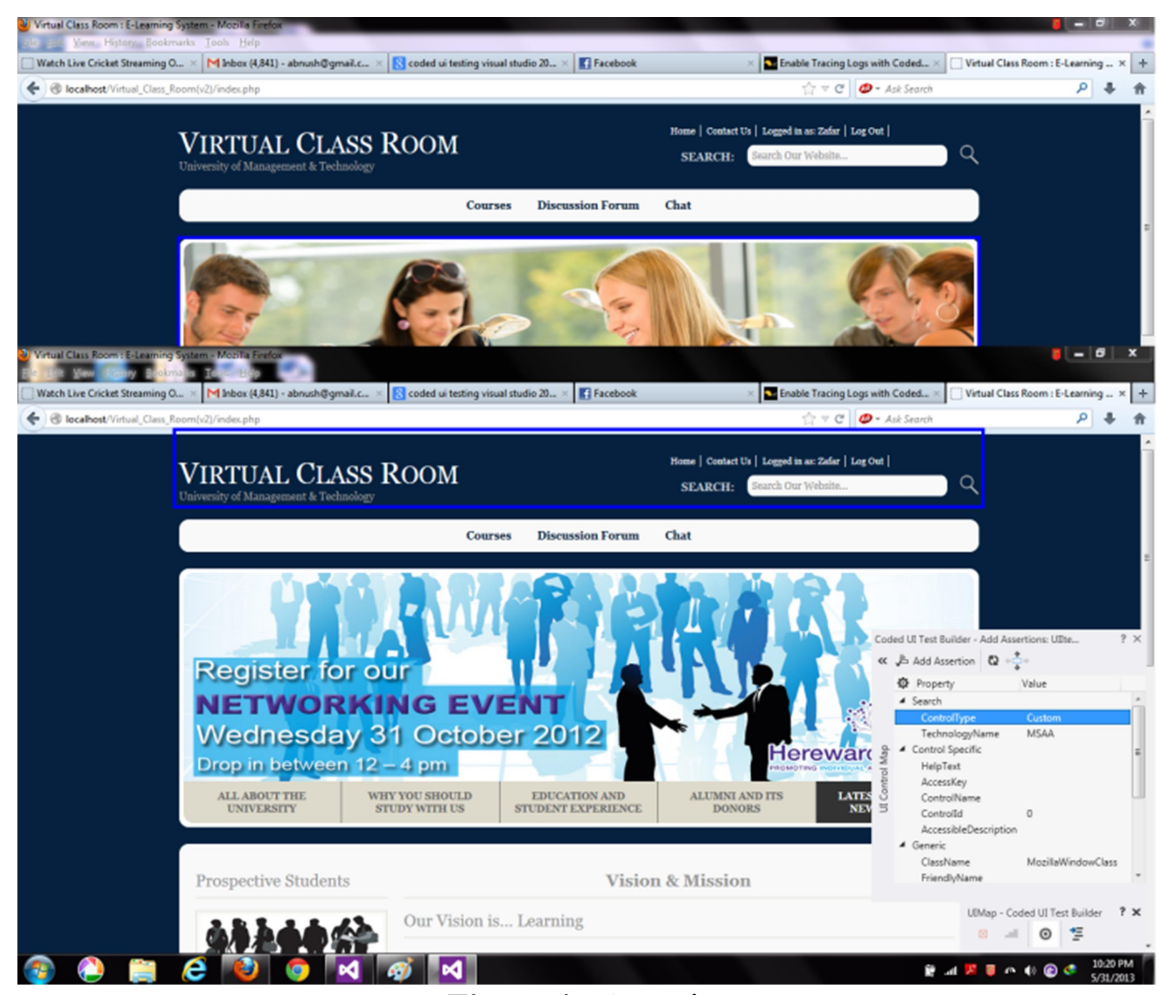

Figure 4:- Assertion

After generating the code assertion is added to check if the forms and tables are placed according to the standards. Figure-4 shows the steps of adding assertions to the use case login.

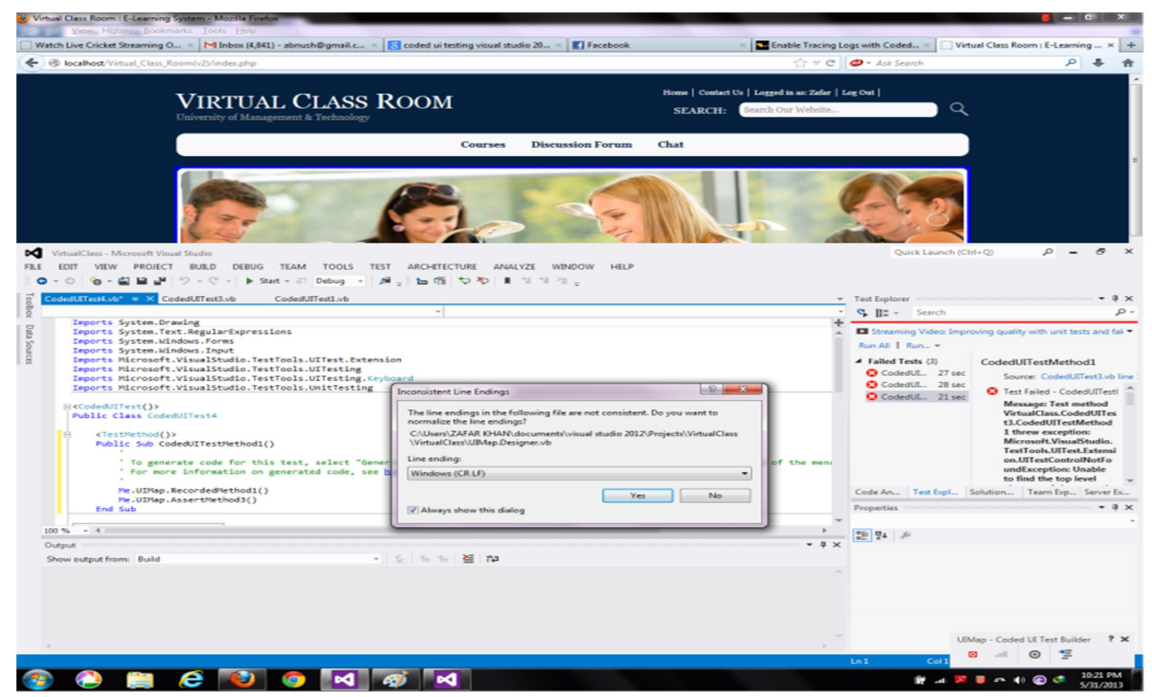

Figure 5:- Assertion

After adding assertion and generating the code for the added assertions, Figure- 5 boxes appeared with warning which showed that the above selected table was not appropriate; it is modified automatically by clicking the yes button. Some of the tests for the login use case were unsuccessful, but after modification all the tests were passed. 


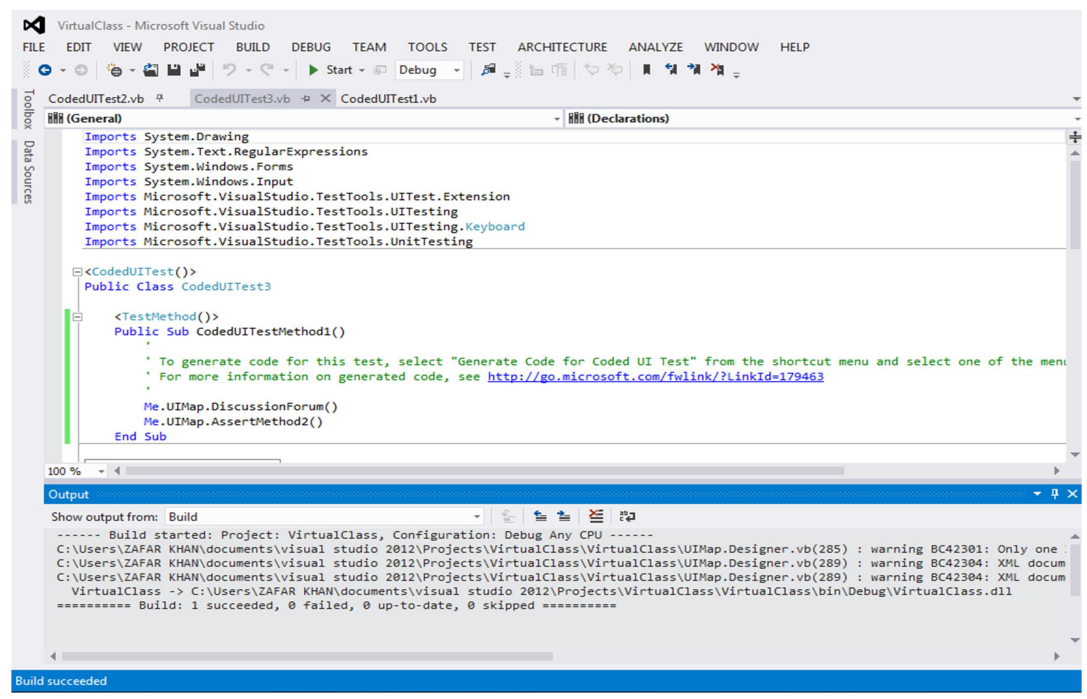

Figure 6:- Running the code

After running the generated code the project is successfully built for the login test.

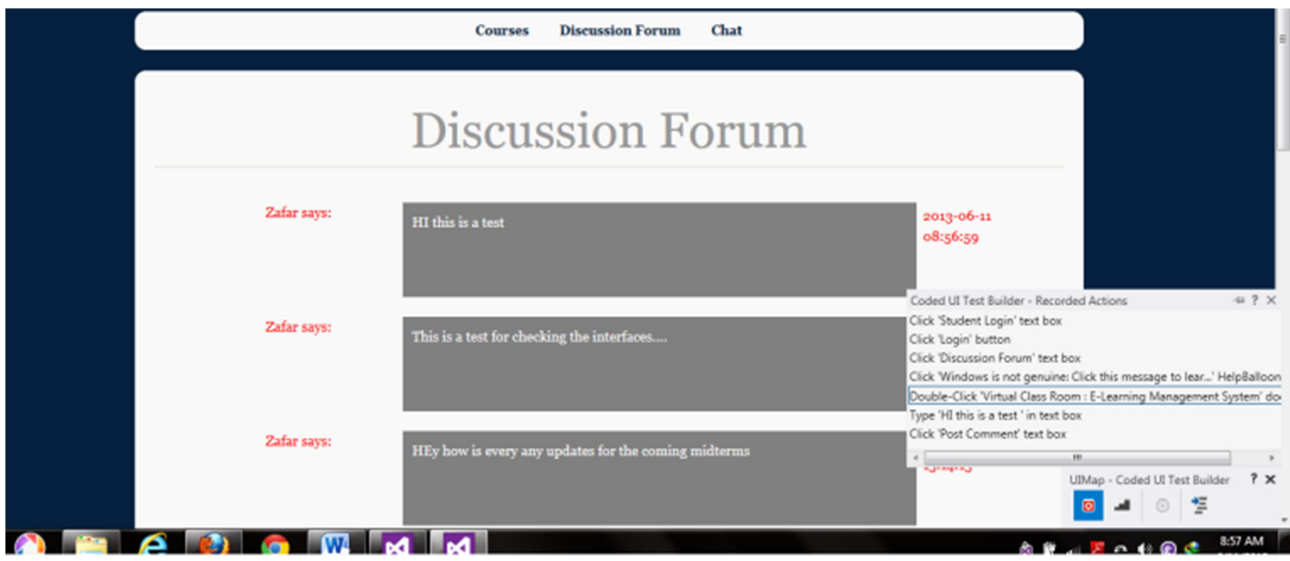

Figure 7:- Testing Discussion Forum

The text on the bottom right of the screen in Figure- 7 shows the start of recording test for the discussion forum.

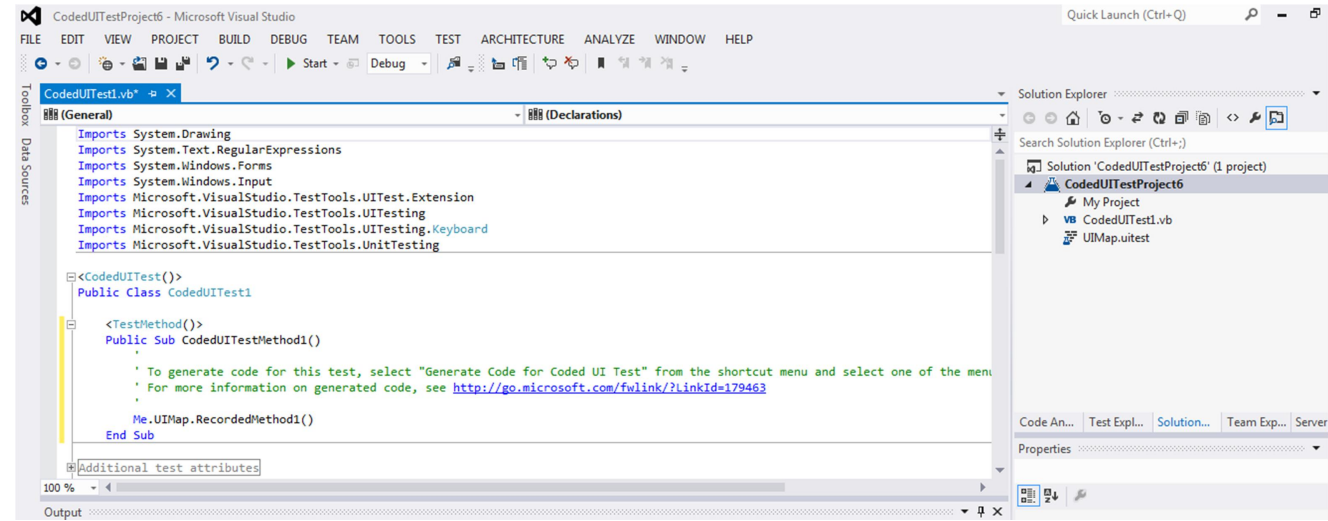

Figure 8:- Code generation for discussion forum 
This is the Code generated for testing Discussion Forum.

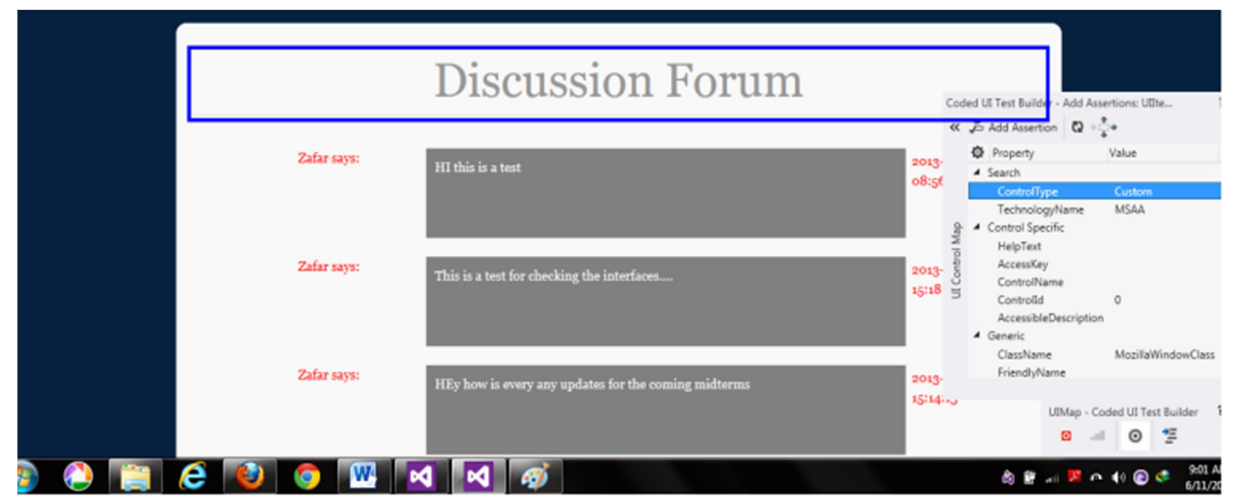

Figure 9:- Adding Assertion

Now we added assertions to the Discussion Forum as shown in Figure-9. We can also generate code for assertions. This is another advantage of Microsoft Visual Studio 2012 Ultimate.

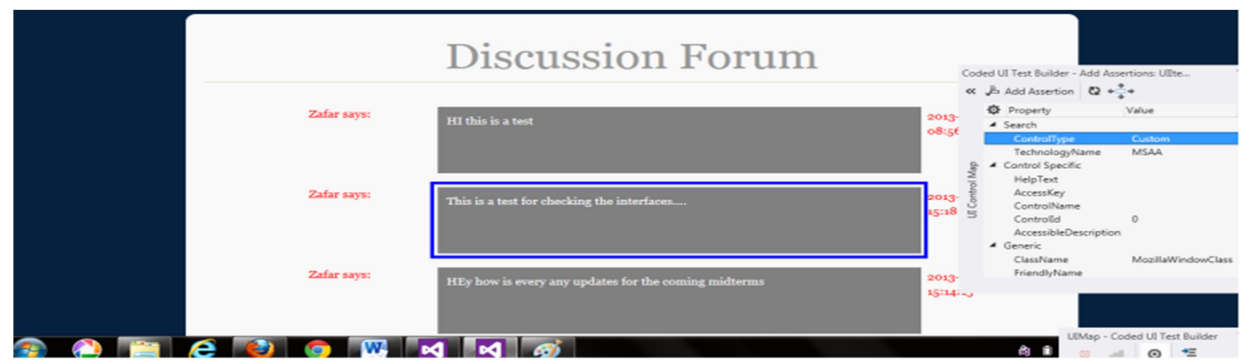

Figure 10:- Adding another assertion to discussion forum

Assertions are added to the discussion forum, as can be seen in Figure-10 where the text box in the center of the webpage is highlighted. We can even add more assertions to the same test case.

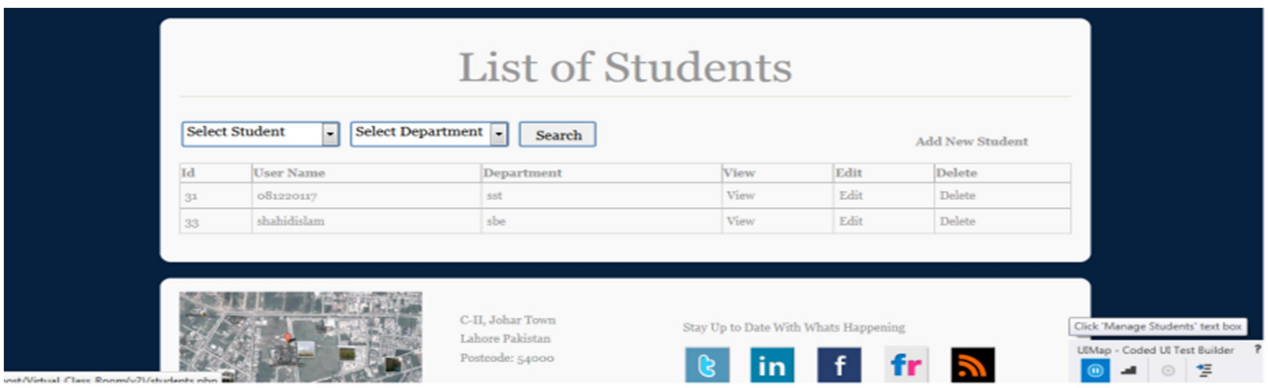

Figure 11:- Testing Manage Students GUI

This is the starting of the test for use case Manage Students as shown in Figure-11. All the steps are recorded for the above mentioned use case and after pausing the recording the recorded steps can be viewed later from the button Recorded Steps. This gives us a clear view of what we have done through the whole recording process. 


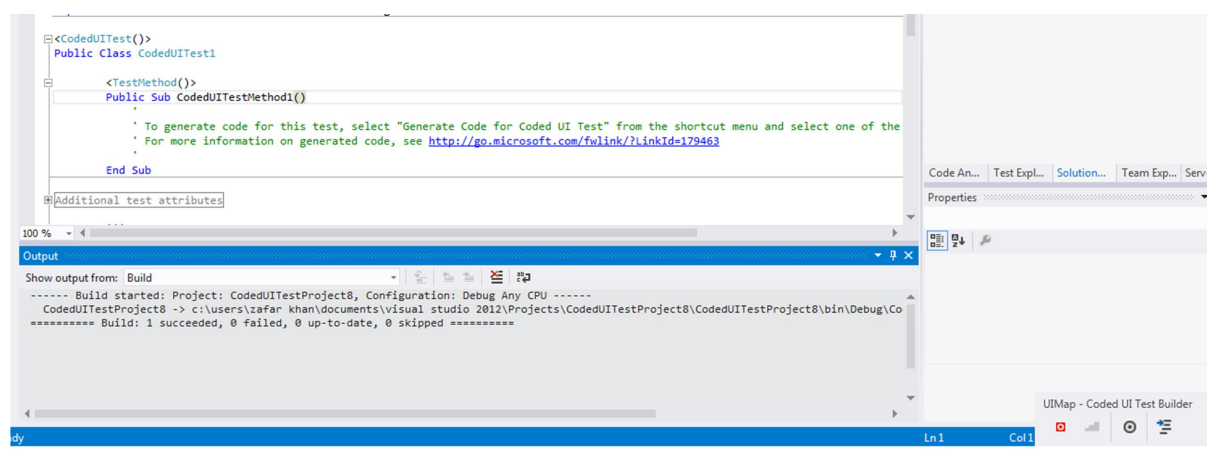

Figure 12:- Code Generated for managing students

The code generated for testing the manage student use case as shown in Figure 12.

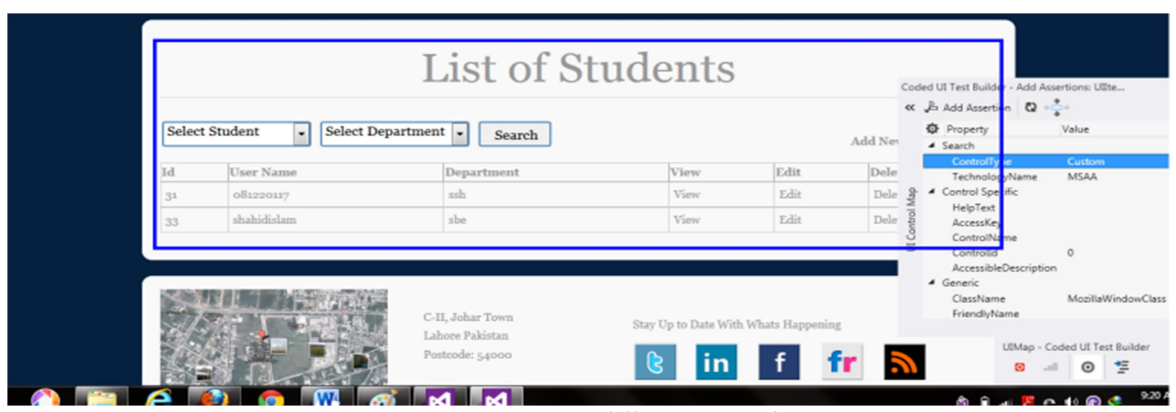

Figure 13:- Adding Assertion

The highlighted box show adding of Assertions for managing students.

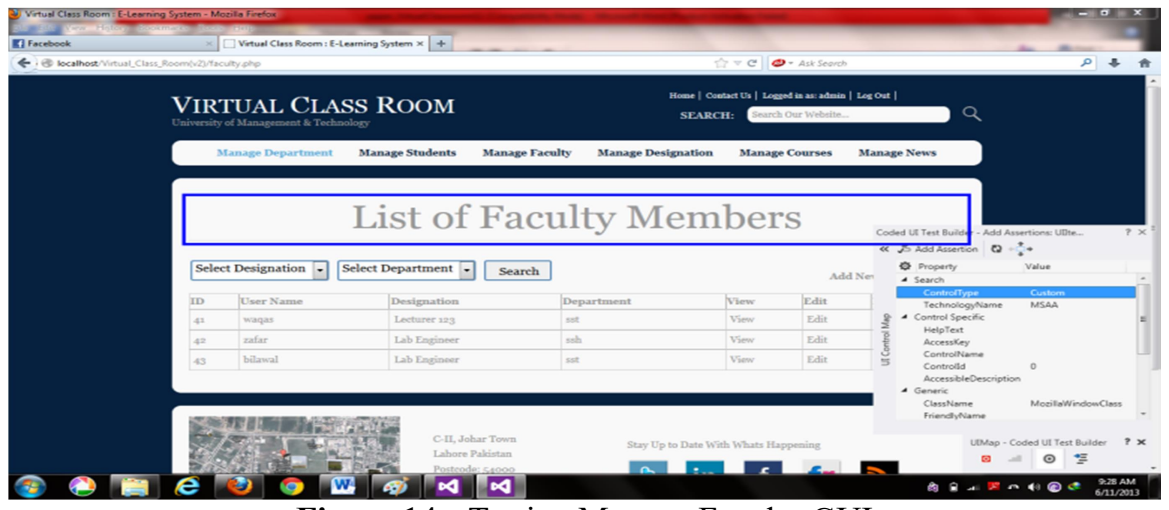

Figure 14:- Testing Manage Faculty GUI

This is the start of recording test for the use case Managing Faculty as shown in Figure-14.

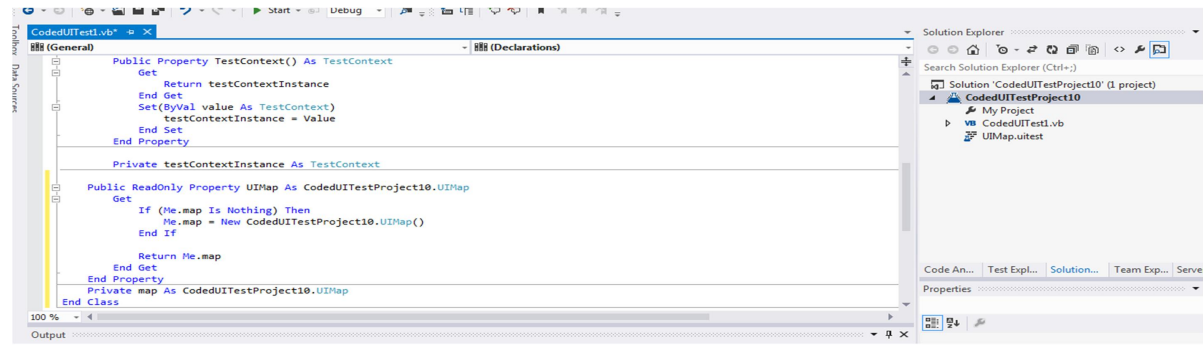

Figure 15:- Code Generated for managing faculty. 
In the Figure-15, the code is generated automatically for the use case Manage Faculty.

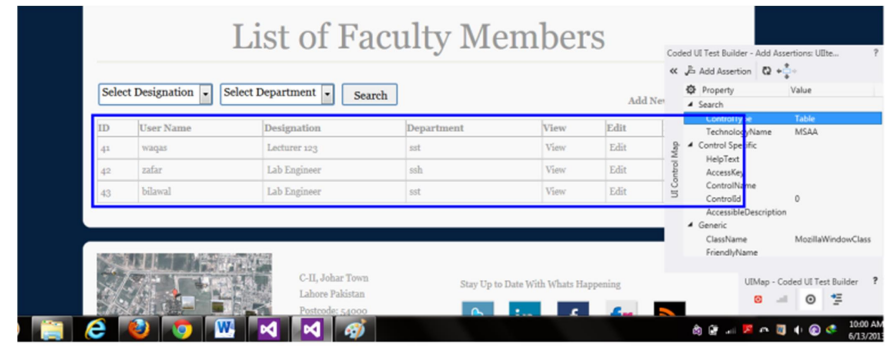

Figure 16:- Adding Assertions

Figure-16 shows the assertions added to the Manage faculty use case.

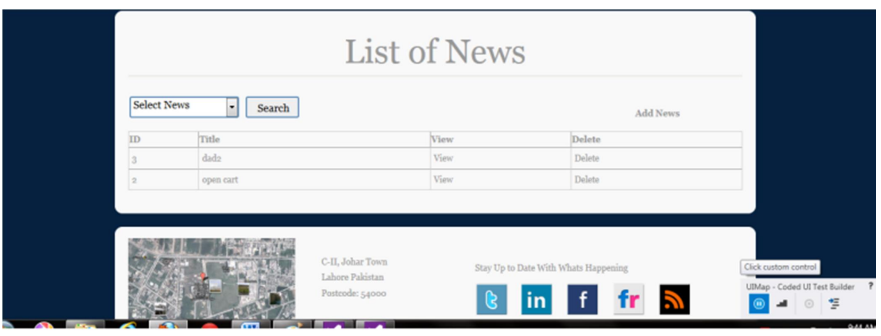

Figure 17:- Starting test for Managing News

In Figure-17, the starting of recording test for the use case Manage News is shown.

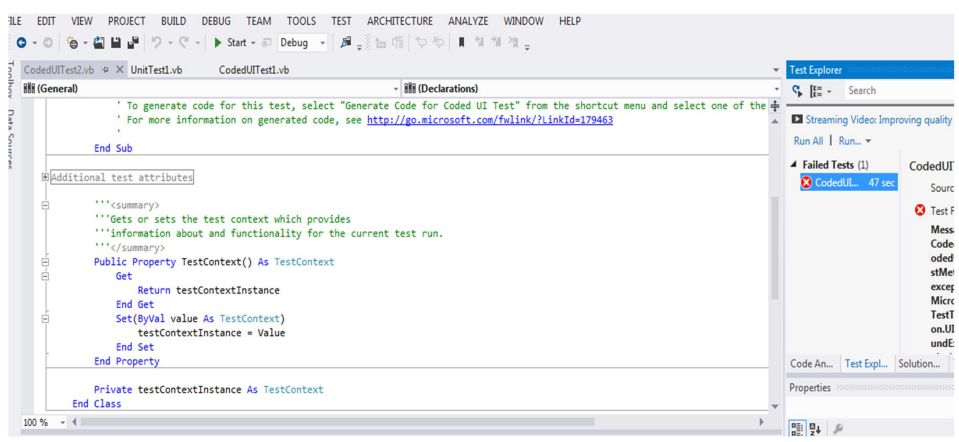

Figure 18:- Code generated for Managing News

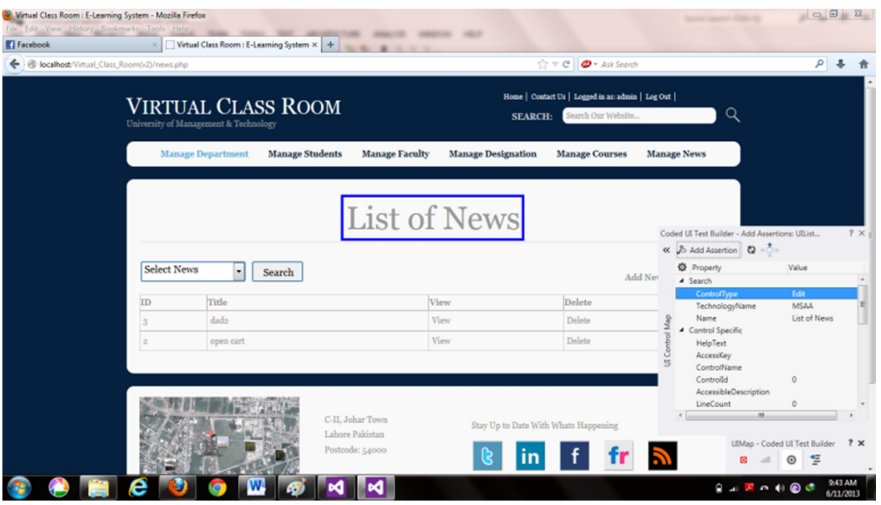

Figure 19:- Adding Assertion 
Figure 19 shows that assertions are added to the above use case Manage News.

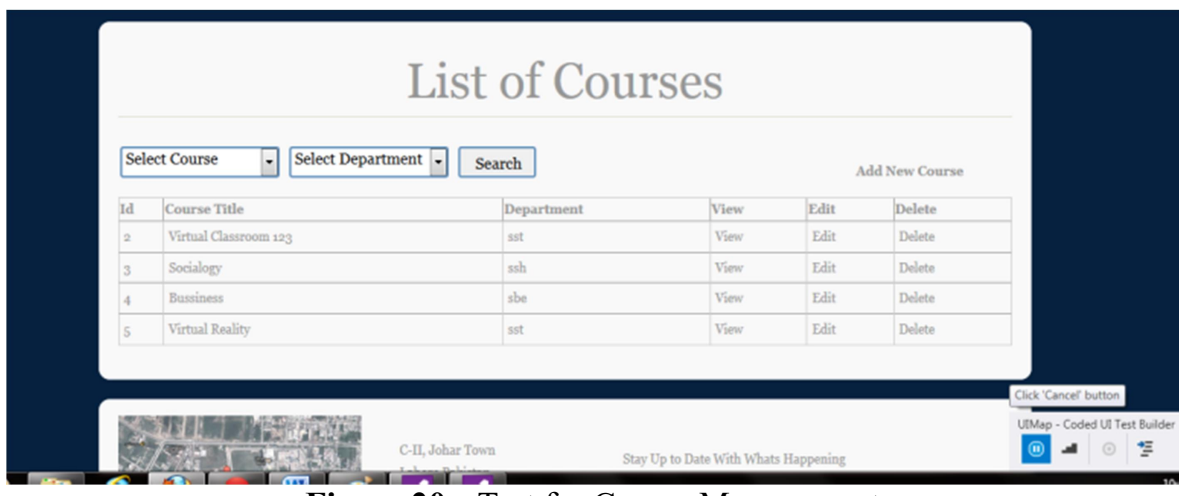

Figure 20:- Test for Course Management

Figure-20 shows the test for Course Management.

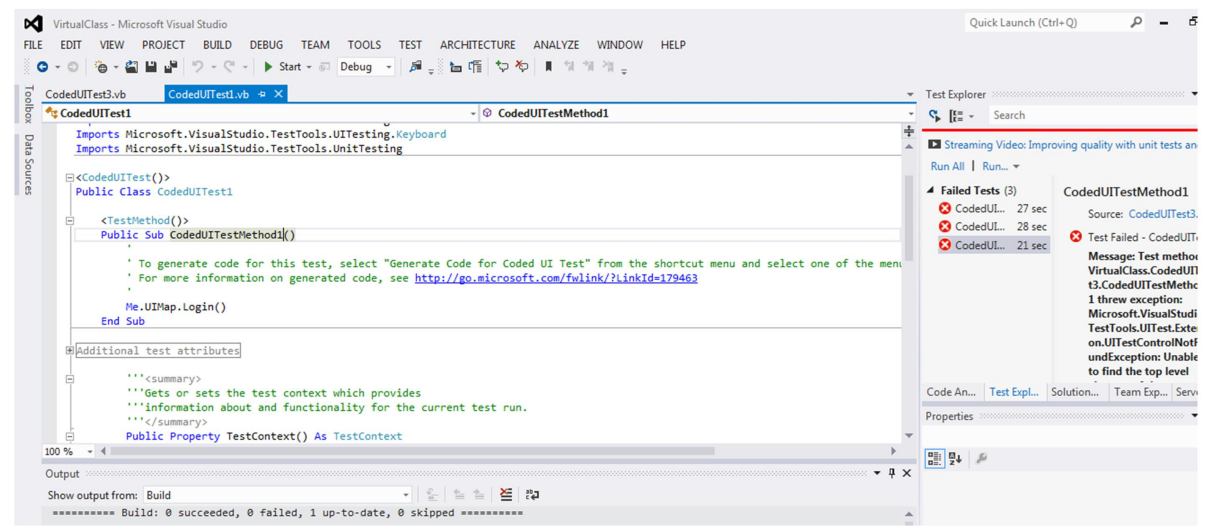

Figure 21:- Code generated for the Course Management

Figure-21 shows the code generated for the Course Management

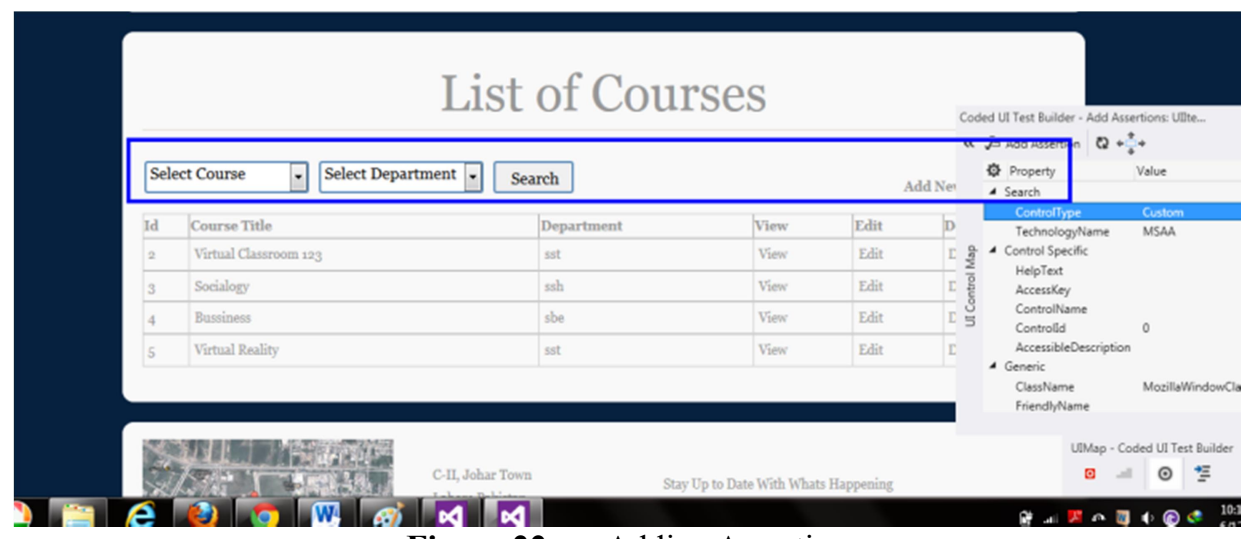

Figure 22:- Adding Assertion

Figure-22 shows that assertions are being add to the Course Management. 


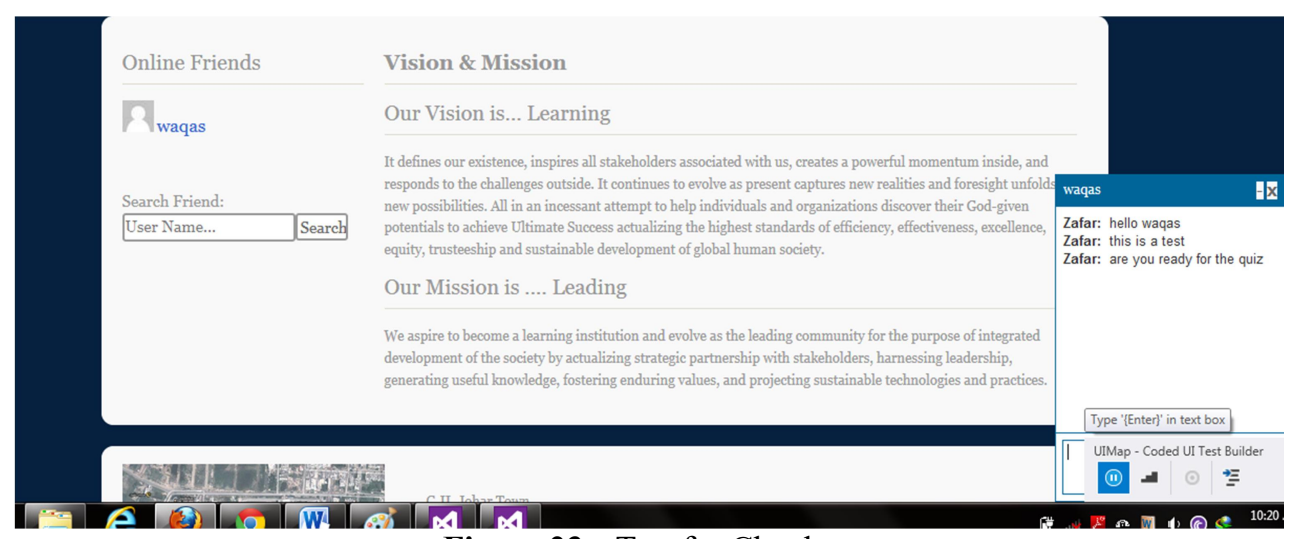

Figure 23:- Test for Chat box

Figure 23-25 shows the Chat box, its generated code and its assertions.

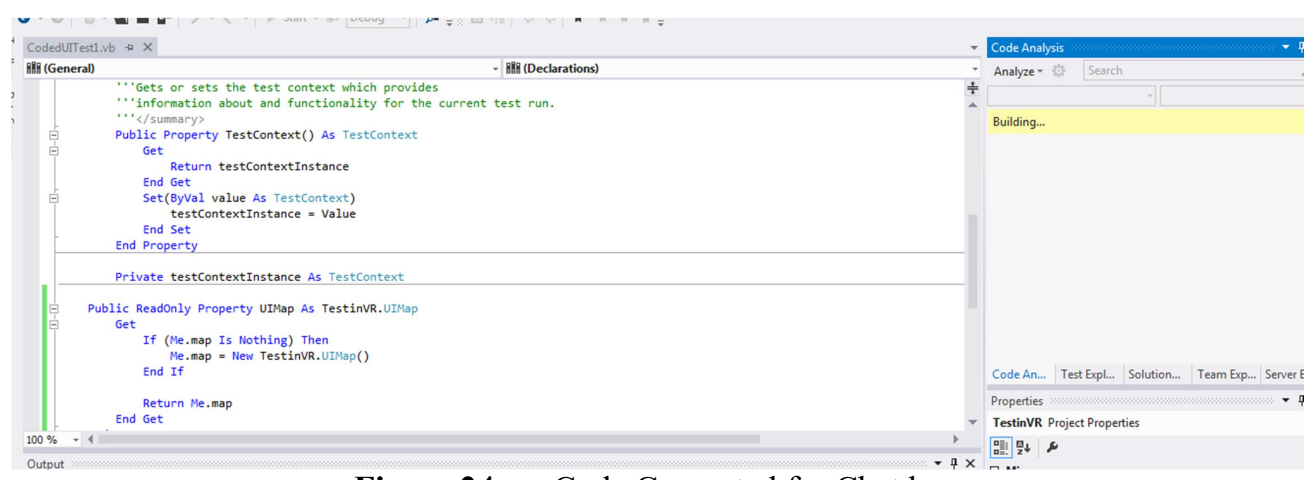

Figure 24:- Code Generated for Chat box

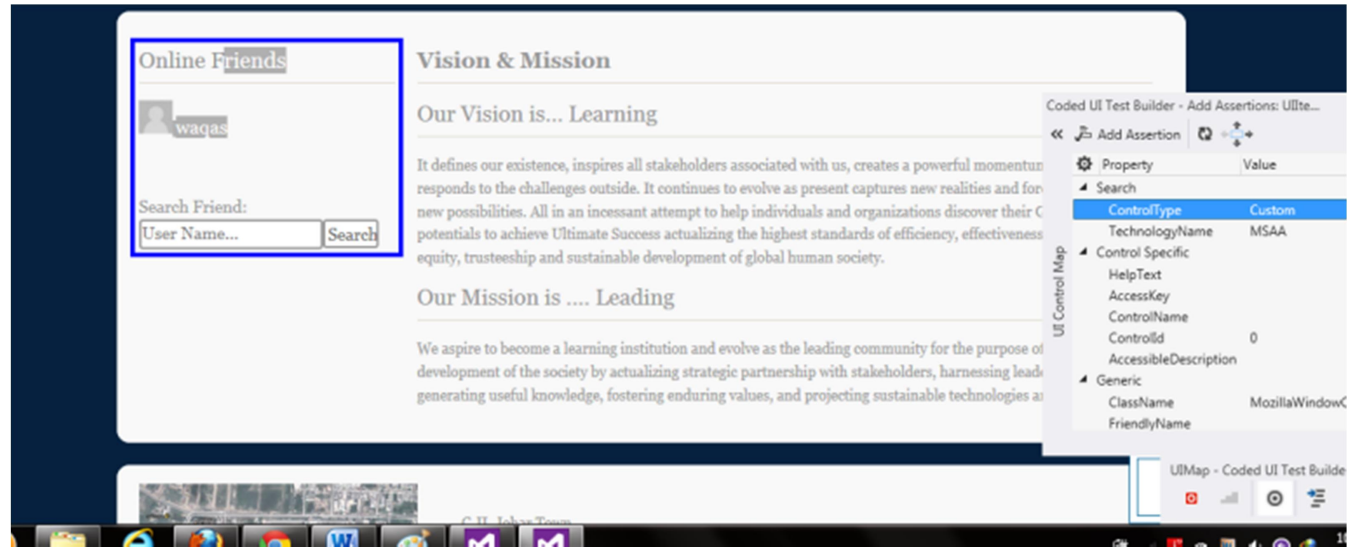

Figure 25:- Adding Assertions to Chat Box

Conclusion and Future Work. The Virtual Classroom will improve the distance learning system by providing the architecture of a real class room. It will be using an internet browser and can work with both local host and server. In future, there are opportunities for the use of the technology to facilitate multiple courses, material used across different courses and training on the job. This will not only reduce educational costs but it will help students to get high quality education from their homes and will also save the travelling expense. Besides, it helps women with a restriction to go out of their homes to acquire education.

The Virtual Classroom can be improved in future with online streaming without any breakdown using dedicated severs. Load balancing of these servers would allow more reliable architecture. It can enable 
faculty to facilitate in evaluating student's performance during the lecture. There will also be a shared white board like a notepad or a wordpad where the students will be able to see what the faculty member is writing on it. This white board will greatly impact in enhancing the understanding of students and promoting an interactive teaching. The other major improvement that we want to make is to allow the students to generate an audio interrupt when they have any question during the lecture; this will help to make the understanding much better. For teachers to evaluate the student's performance based on the participation in the class, we will implement the feature of a graph, which will highlight the students who are active and regularly participating in the class activities.

Acknowledgment.We would like to acknowledge and extend our heartfelt gratitude to the persons who have made the completion of this research possible. We are thankful to Miss Saira Osama for her understanding and assistance, Miss Farah Sarwar for assisting us in the data collection of virtual reality.

\section{REFERENCES}

[1] Hiltz, S. R. (1994). The virtual classroom: Learning without limits via computer networks. Intellect Books.

[2] Rao, U., \& Turoff, M. (1990). Hypertext functionality: A theoretical framework. International Journal of Human-Computer Interaction, 2(4), 333-357.

[3] Whitescarver, J., Mukherji, P., Turoff, M., DeBlock Jr, R. J., Czech, R. M., \& Paul, B. K. (1987, August). A network environment for computer-supported cooperative work. In ACM SIGCOMM Computer Communication Review (Vol. 17, No. 5, pp. 260-272). ACM.

[4] Quinn, C. N., Mehan, H., Levin, J. A., \& Black, S. D. (1983). Real education in non-real time: The use of electronic message systems for instruction. Instructional Science, 11(4), 313-327.

[5] Yang, A. (2003). Web-based asynchronous synchronous environment for online learning. USDLA Journal, 17(2), 5-18.

[6] KMC On Demand - CE Credits | Adjusters eLearning | Insurance Adjuster Continuing Education. Retrieved from https://www.kmcondemand.com/portal/index.php?Page=dynamic\&id=5.

[7] Milošević, I., Živković, D., Arsić, S., \& Manasijević, D. (2015). Facebook as virtual classroom-Social networking in learning and teaching among Serbian students. Telematics and Informatics, 32(4), 576-585.

[8] Global Virtual Classroom: A Free Online Educational Program. Retrieved from http://www.virtualclassroom.org/history.html\#.UZx6H1d1zjM.

[9] Moodle - Wikipedia. Retrieved from https://en.wikipedia.org/wiki/Moodle.

[10] Omoregbe, N. A., Azeta, A. A., Bello-Osagie, U., \& Agarana, M. C. (2015). Design And Implementation Of A Virtual Classroom System.

[11] Christy, K. R., \& Fox, J. (2014). Leaderboards in a virtual classroom: A test of stereotype threat and social comparison explanations for women's math performance. Computers \& Education, 78, 66-77.

[12] Imaginet, Getting Started with Coded UI Testing: Building Your First Automated Retrieved from https://www.slideshare.net/Imaginet/your-first-coded-ui-16921540

[13] Binary Clips Retrieved from http://www.binaryclips.com/.

[14] Data Driven Coded UI Test using Visual Studio 11 Retrieved from http://www.dotnetcurry.com/visualstudio/798/data-driven-codedui-test-visual-studio

[15] Analytics for flow chart for virtual class room Retrieved from http://www.it.iitb.ac.in/ praj/acads/Virtual\%20Classroom.ppt . .

[16] World Education Center Retrieved from http://wecindia.com/ .

[17] 7 Widely-Used And Open Source E-Learning Applications Retrieved from http://www.webresourcesdepot.com/7-widely-used-and-open-source-e-learning-applications/ .

[18] Deskra LMS Virtual Classroom Retrieved from http://www.deskera.com/lms/virtual-classroom-in-lms .

[19] BigBlueButton Retrieved from http://www.bigbluebutton.org/

[20] A Discrete-Event Network Simulator Retrieved from http://www.nsnam.org/doxygen-release/classns3_1_1_udp_socket.html 
[21] Kimovski, G., Trajkovic, V., \& Davcev, D. (2001). Virtual laboratory-agent-based resource sharing system. In Technology of Object-Oriented Languages and Systems, 2001. TOOLS 39. 39th International Conference and Exhibition on (pp. 89-98). IEEE.

[22] Tiwari, A., Tiwary, A., \& Bhatt, Y. (2010, November). A distributed web conferencing architecture to meet inorganic training needs of an enterprise. In Education and Management Technology (ICEMT), 2010 International Conference on (pp. 636-640). IEEE.

[23] Hariharan, B., Joy, N., \& Sreedevi, A. G. (2013, May). Multimedia: Video sharing for e-classroom. In Wireless and Optical Communication Conference (WOCC), 2013 22nd (pp. 372-377). IEEE.

[24] Kimovski, G., Trajkovic, V., \& Davcev, D. (2001, August). Resource manager for distance education systems. In icalt (p. 0387). IEEE.

[25] Bose, R. (2004, April). Information technologies for education \& training in e-government. In Information Technology: Coding and Computing, 2004. Proceedings. ITCC 2004. International Conference on (Vol. 2, pp. 203-207). IEEE. 